\title{
Correlation Between Microstructure and Mechanical Properties of 2219-T8 Aluminum Alloy Joints by VPTIG Welding
}

\author{
Lan-Qiang Niu ${ }^{1} \cdot{\text { Xiao-Yan } \mathrm{Li}^{1} \cdot \text { Liang Zhang }^{1} \cdot \text { Xiao-Bo Liang }}^{1} \cdot \mathrm{Mian}_{\mathrm{Li}^{1}}$
}

Received: 24 August 2016/Revised: 16 October 2016/Published online: 19 November 2016

(C) The Chinese Society for Metals and Springer-Verlag Berlin Heidelberg 2016

\begin{abstract}
In this study, 2219-T87 aluminum alloys were butt welded by the double-pass tungsten inert gas arc welding process. And the softening behavior of fusion zone (FZ) and heat-affected zone (HAZ) was evaluated with the analysis of welding temperature field, grain size, alloying element distribution and precipitates evolution. Results show that the two FZs are almost the weakest regions in the joint, where the microhardness value is 76 and $78 \mathrm{HV}$, respectively. Microhardness of the HAZ generally grows along with increasing distance from fusion line except a valley value at the distance of about $4.5 \mathrm{~mm}$. The mean grain size of two FZs is about 74.4 and $79.2 \mu \mathrm{m}$, whereas $41.5,44.9$ and $43.4 \mu \mathrm{m}$ for the two measured HAZs and base metal (BM), respectively. There is about $60.4 \%$ and $54.2 \% \mathrm{Cu}$ consumed in the coarse whitish particles of FZs that have little strengthening effect, while the percentage is about $24.6 \%$ of BM that is almost the same as HAZ. A large number of strengthening phases $\theta^{\prime}$ distribute dispersively in BM, whereas hardly any precipitates exist in FZ and HAZ adjacent to FZ. So the coarsening of grain size, reduction and segregation of alloying element content, and the precipitate evolution are regarded as the main causes of softening in FZ, while the precipitate evolution is the main factor of softening in HAZ.
\end{abstract}

KEY WORDS: 2219-T87 Aluminum alloy; TIG welding; Fusion zone; Heat-affected zone; Softening behavior

\section{Introduction}

The 2219 aluminum alloy is basically $\mathrm{Al}-\mathrm{Cu}-\mathrm{Mn}$ ternary alloy with small additions of $\mathrm{Ti}, \mathrm{V}$ and $\mathrm{Zr}$. It is a kind of heattreatable alloy with admirable mechanical properties over a wide temperature range from -250 to $250{ }^{\circ} \mathrm{C}$ [1]. It is widely used in the aerospace industry, especially for the manufacture of liquid cryogenic rocket fuel tanks, due to its unique combination of properties such as good weldability, high specific strength and superior cryogenic properties [2, 3].

Available online at http://link.springer.com/journal/40195

Lan-Qiang Niu

niulanqiang@163.com

1 College of Materials Science and Engineering, Beijing University of Technology, Beijing 100124, China
The alloy 2219 is considered to possess good weldability in consequence of the low welding crack tendency, and it can be easily welded using most welding processes, such as variable polarity plasma arc (VPPA) welding, variable polarity tungsten inert gas (VPTIG) arc welding and friction stir welding (FSW) [4-8]. And in the present, double-pass welding method with TIG helium arc welding as the first pass and VPTIG argon arc welding as the second pass is one of the widely used welding processes in production due to the good flexibility, reliable quality and low cost.

During the TIG welding of aluminum alloys, the solute in the FZ is completely redistributed by the solidification process. And in the HAZ, the material suffers from a solidstate heat treatment so that the nanometric precipitates are changed a lot. All these variations of microstructure always lead to softening of the joint. So it is important to have a complete understanding of the softening behavior in both 
the FZ and the HAZ in order to reduce the strength loss of the joint. Massive work was done about the effects of welding method and post-weld heat treatment on microstructure and mechanical properties of the 2219 aluminum alloy weld joints [9-16]. However, very few detailed studies were focused on the influencing factors of softening by welding (e.g., precipitates evolution, grain size, alloying elements content); particularly, the softening behavior of FZ and HAZ is not entirely clear. So in this study, the softening behavior of 2219 alloy weld joint is systematically studied, with emphasis on the welding temperature field, the differences of grain size, alloying element distribution and precipitates evolution in different regions of the joint.

\section{Materials and Methods}

\subsection{Materials}

The BM used in this study was 6-mm-thick 2219-T87 aluminum alloy, and the filler metal was 2325 (Al-CuMn), which is developed by Aerospace Research Institute of Materials and Processing Technology, China. The chemical compositions of BM and filler metal are shown in Table 1.

\subsection{TIG Welding Process}

The butt welding without groove was conducted by the double-pass TIG arc welding process, using an automatic TIG welding machine equipped with the wire feeder. And the gap between BMs was $1 \mathrm{~mm}$. The welding direction was perpendicular to the rolling direction of BM. The schematic diagram of the backing weld and capping weld is shown in Fig. 1. And the process parameters of welding are listed in Table 2.

\subsection{Analysis Methods}

Microhardness measurements were carried out on cross section of the joint from weld center to BM using a HXD1000TM/LCD microhardness tester with the load of $1000 \mathrm{gf}$ and dwell time of $10 \mathrm{~s}$. The distance between two adjacent test points is $0.3 \mathrm{~mm}$, and the Vickers' hardness

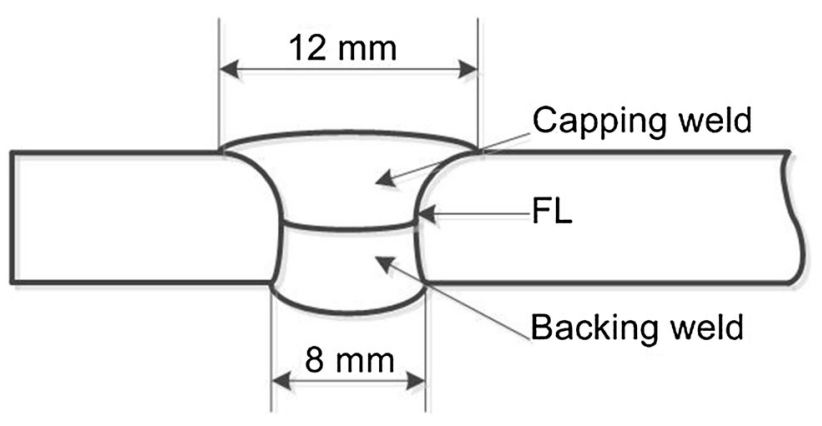

Fig. 1 Schematic diagram of the backing weld and capping weld

profiles were obtained by the average value of three measurements at each position.

The grain size of FZ, HAZ and BM was measured by an electron back-scattered diffraction (EBSD) system equipped with an FEI QUANTA FEG 650 scanning electron microscope (SEM). Specimens for EBSD were prepared by conventional mechanical polishing followed by electrochemical polishing. The polishing solution is $20 \mathrm{ml}$ ethylene glycol monobutyl ether $+40 \mathrm{ml}$ perchloric acid $+140 \mathrm{ml}$ ethanol.

The alloying element distributions in FZ, HAZ and BM were analyzed by the back scatter electron imaging of SEM. And the chemical compositions of primary phases and matrix were analyzed using energy-dispersive spectrometer (EDS).

The nanometric precipitates in different zones of the joint were observed with a JEM2010 TEM at $200 \mathrm{kV}$. The TEM specimens were prepared by sectioning, mechanical polishing down to $100 \mu \mathrm{m}$, and followed by double-jet electro-polishing at $15 \mathrm{~V}$ in a solution of $30 \%$ nitric acid and $70 \%$ methanol solution cooled to $-30{ }^{\circ} \mathrm{C}$.

The temperature condition in different locations of weldment was achieved using the Visual-Weld simulation software [17, 18].

\section{Results and Discussion}

\subsection{Microhardness Profile}

The microhardness profile is shown in Fig. 2. It can be seen that the FZs and HAZ exhibit obvious softening behavior. The two FZs whose microhardness values are about 76 and

Table 1 Chemical compositions of the BM and filler metal (wt \%)

\begin{tabular}{lllllllll}
\hline & $\mathrm{Cu}$ & $\mathrm{Mn}$ & $\mathrm{Zr}$ & $\mathrm{Ti}$ & $\mathrm{V}$ & $\mathrm{Fe}$ & $\mathrm{Si}$ \\
\hline 2219 & $5.8-6.8$ & $0.2-0.4$ & $0.10-0.25$ & $0.02-0.1$ & $0.05-0.15$ & 0.3 & 0.2 & $\mathrm{Al}$ \\
2325 & $6.0-6.8$ & $0.2-0.4$ & - & $0.1-0.2$ & - & - & - & Bal. \\
\hline
\end{tabular}


Table 2 Process parameters of the TIG welding

\begin{tabular}{|c|c|c|c|c|c|c|}
\hline & $\begin{array}{l}\text { Welding } \\
\text { current (A) }\end{array}$ & $\begin{array}{l}\text { Welding } \\
\text { voltage }(V)\end{array}$ & $\begin{array}{l}\text { Welding } \\
\text { speed }(\mathrm{mm} / \mathrm{s})\end{array}$ & $\begin{array}{l}\text { Angle of } \\
\text { electrode tip }\end{array}$ & Shield gas & $\begin{array}{l}\text { Flow rate of } \\
\text { shield gas }(\mathrm{L} / \mathrm{min})\end{array}$ \\
\hline Backing welding & $185-192$ & 15 & 5.0 & $60^{\circ}$ & $\mathrm{He}$ & 11 \\
\hline Capping welding & $265-280$ & 15 & 2.2 & $60^{\circ}$ & $\mathrm{Ar}$ & 9 \\
\hline
\end{tabular}

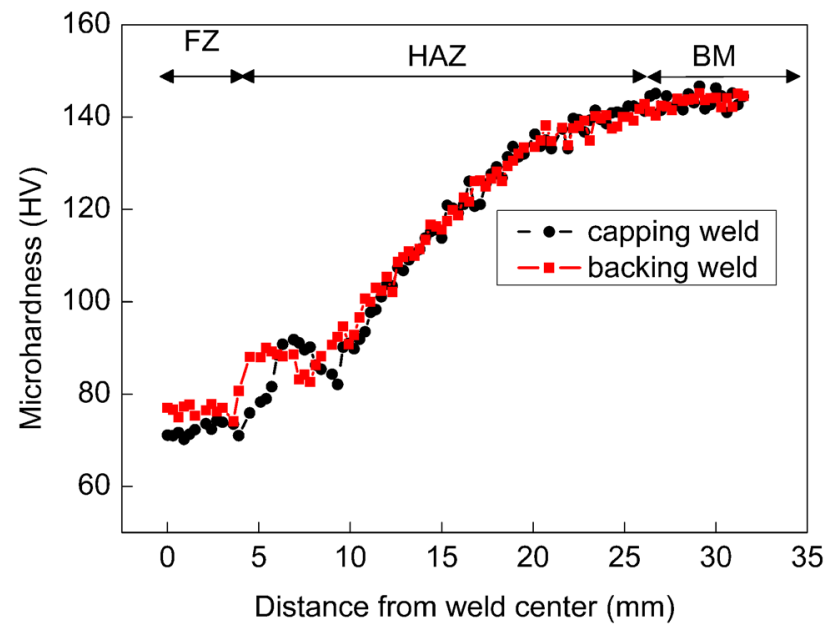

Fig. 2 Microhardness profile of the welding joint

$78 \mathrm{HV}$, respectively, are almost the weakest zones in the joint. The microhardness in HAZ adjacent to FZ with a certain width keeps higher value and then reaches a valley value at a distance of about $4.5 \mathrm{~mm}$ from fusion line (FL), which represents the boundary of bond zone and HAZ. In the HAZ far away from FZ, microhardness increases along with increasing distance from FL; finally, the value reached is the same as that of BM at about $22 \mathrm{~mm}$ away from FL.

It is well known that strength of aluminum alloys is related closely to four main factors which are grain size, dislocation density, solid solubility and precipitate. The FZ was the casting-state structure with few dislocations, and the BM has suffered from high-temperature treatment before welding and dislocations were easily dissipated. So in the present study, the dislocation density can be ignored for discussing softening behavior. The other three factors will be analyzed in the following sections.

\subsection{Grain Morphology and Size}

The EBSD has been widely used to study the grain morphology instead of traditional optical microscopy in recent years due to its high clarity and accuracy. The grain morphology and size in FZ, HAZ and BM were analyzed by EBSD, respectively, and the results are shown in Fig. 3. It should be noted that HAZ includes two different zones, one is close to the weld seam and the other is about $11 \mathrm{~mm}$ far from the FL which is about in the middle of the HAZ.
As shown in Fig. 3a-e, the grains with different orientations are marked on different colors, and the high-angle grain boundaries over $15^{\circ}$ misorientation are drawn by continuous thin lines. Meanwhile, the grain size statistics measured by the HKL CHANNEL5 software are listed at the right of them. From Fig. 3a, b, it can be seen that grains in FZ of both backing and capping weld are dendritic equiaxed grains, and the mean grain sizes are 74.4 and $79.2 \mu \mathrm{m}$, respectively, according to the statistic results. In addition, the backing welding generates a slightly finer grain in FZ than capping welding. That is mainly due to the fact that the heat input of backing weld is lower, the weld pool size is smaller, so the weld pool solidifies more rapidly, the degree of supercooling is higher, and the nucleation of grains is promoted, while grain growth is inhibited.

Figure 3c-e shows the grain morphology in HAZ and $\mathrm{BM}$; it can be seen that grains in both HAZ and BM are all elongated along the rolling direction and maintain the pancake morphology. According to the statistic, the mean sizes of most grains in the two HAZs and BM are 41.5, 44.9 and $43.4 \mu \mathrm{m}$, respectively. That is to say that the grains in HAZ are not obvious coarsening in comparison with those in BM. Meanwhile, the degree of recrystallization is analyzed through statistic of the internal average misorientation angle within the grains, and the result is that the degrees of recrystallization of HAZ and BM are 9.89\%, $10.7 \%$ and $7.83 \%$, respectively. So the weld heat input has little effect on the grain size and degree of recrystallization in HAZ.

According to the classical Hall-Petch relationship, grain coarsening is one cause of softening of the FZ, while the grain size is not recognized as the factor of softening of HAZ.

\subsection{Alloying Elements Distribution}

The main factors affecting the mechanical properties of aluminum alloy, except grain, also include solid solubility and precipitation phase distribution, and these two factors are closely related to the content and distribution of alloying elements. So the back scatter electron images and EDS of second phases of FZ, HAZ and BM were taken using SEM. And the results are shown in Fig. 4. The dark areas are Al matrix, and whitish parts are the second phases 

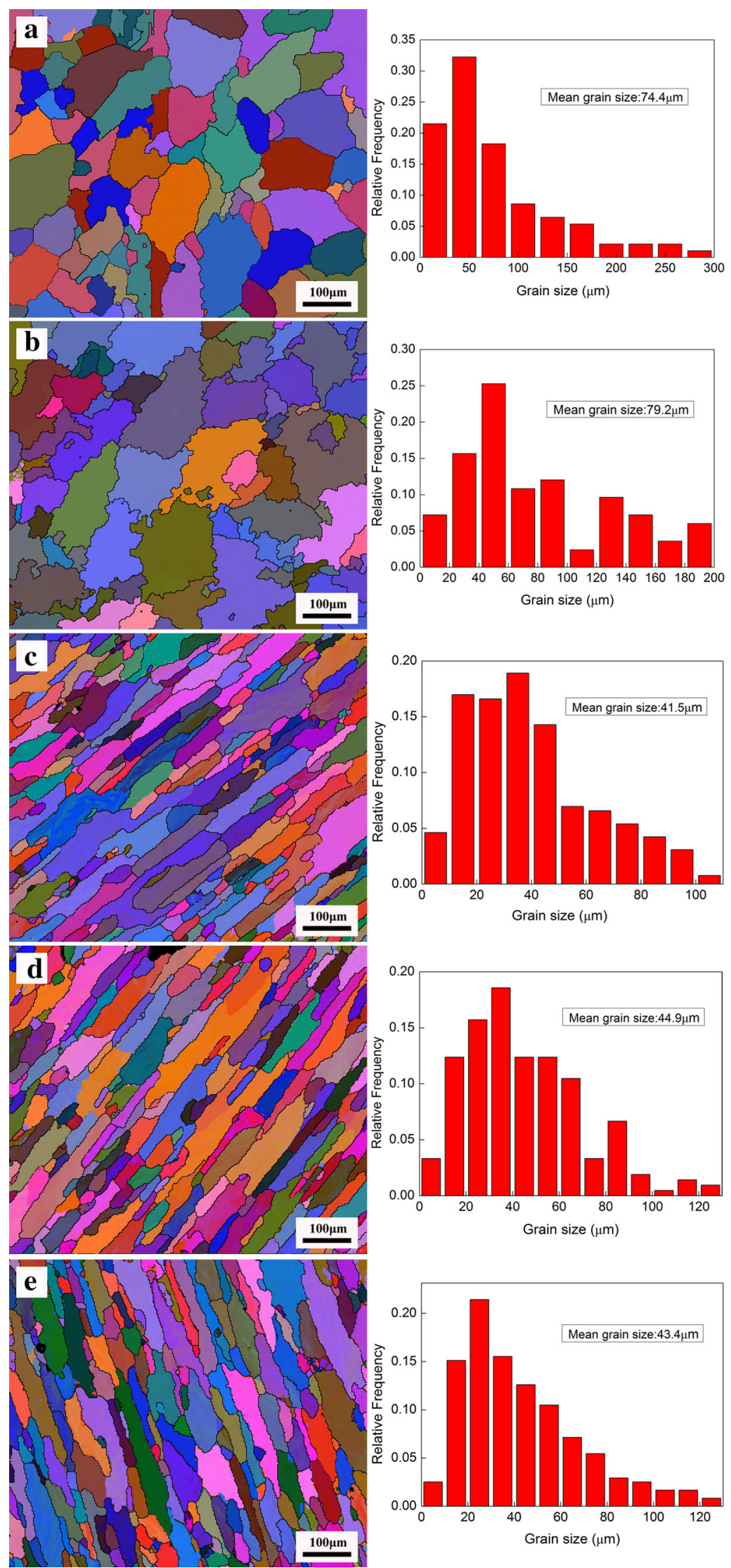
4Fig. 3 Grain morphologies and sizes of different zones in the joint: a FZ of backing weld; b FZ of capping weld; c HAZ close to FL; d HAZ far from FL; e BM

containing many alloying elements. The EDS analysis revealed that these whitish parts had almost same compositions in FZ, HAZ and BM. Table 3 shows the average composition got from five random points.

It can be seen that a large number of second phases exist with a continuous reticular distribution in both FZs from Fig. 4a, b. According to the atomic percent, the white second-phase particles in FZs are preliminarily considered as $\theta$
Table 3 Compositions of second phases in the two FZs and BM (at.\%)

\begin{tabular}{lllll}
\hline & $\mathrm{Al}$ & $\mathrm{Mn}$ & $\mathrm{Fe}$ & $\mathrm{Cu}$ \\
\hline FZ of capping weld & 80.81 & 0.15 & 0.18 & 18.86 \\
FZ of backing weld & 81.32 & 0 & 0.18 & 18.50 \\
BM & 83.62 & 0 & 0 & 16.38 \\
\hline
\end{tabular}

phases. The reason of the formation of this morphology is that the equilibrium distribution coefficient of $\mathrm{Cu}$ is $<1$, which would be segregated at the grain boundaries during the
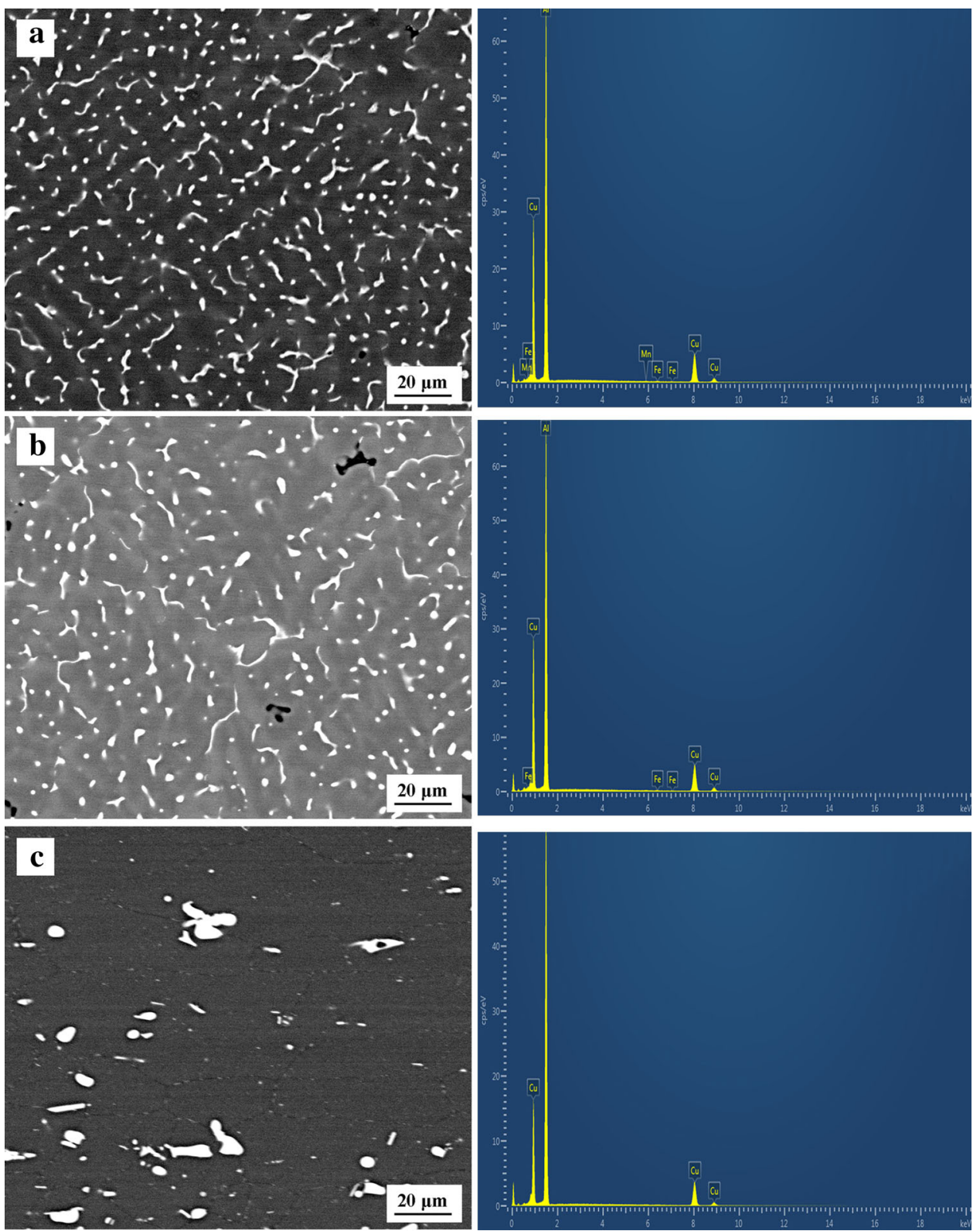

Fig. 4 Backscatter electron images and energy-dispersive spectra of second phases of different zones in the joint: a FZ of backing weld; $\mathbf{b}$ FZ of capping weld; $\mathbf{c}$ BM 
solidification of weld pool. When eutectic reaction occurred, the liquid solidified as solid $\mathrm{Al}$ and $\theta$ phases. Besides, $\theta$ phases existed in the grain boundaries and finally produced these divorced eutectic structure. Figure $4 \mathrm{c}$ exhibits the second phases in BM, because it has experienced T87 treatment, there are a few undissolved particles remained, and they are also $\theta$ phases according to the EDS results. On the other hand, the area statistic conducted by an ImageJ software shows that the area ratios of whitish parts in FZs are about $8.94 \%$ and $8.20 \%$, respectively, whereas it is $4.21 \%$ in $\mathrm{BM}$. Then the ratio of $\mathrm{Cu}$ existing in the whitish parts can be achieved using the following equation [19]:

$r=\frac{f \times C_{\mathrm{p}}}{C}$

where $r$ is the ratio of $\mathrm{Cu}$ existing in the whitish parts; $f$ is the area ratio of whitish parts; $C_{\mathrm{p}}$ is the $\mathrm{Cu}$ composition of the whitish parts, as presented in Table 3; $C$ is the average $\mathrm{Cu}$ composition of FZs or BM.

The results show there are about $60.4 \%$ and $54.2 \% \mathrm{Cu}$ in these whitish parts of FZs that have little strengthening effect, while the percentage is $24.6 \%$ of BM. By the way, the backscatter electron image and whitish part composition of HAZ were found almost the same as those of BM, so it is needless to repeat.

Thus, the alloying element content in matrix of FZ is lower than that of BM leading to softening of the FZ. It is almost the same in HAZ and BM, so it cannot be regarded as the factor of softening of HAZ.

\subsection{Precipitate Distribution}

The variation of the type, quantity and size of nanometric precipitates is always regarded as the main cause of the strength change, as for heat-treatable aluminum alloys. Since $\mathrm{Cu}$ content is over 20 times higher than those of any other alloying elements, 2219 aluminum alloy can be approximatively considered as a binary alloy of $\mathrm{Al}-\mathrm{Cu}$. Previous studies proposed that the full decomposition sequence in $\mathrm{Al}-$ $\mathrm{Cu}$ system is as follows: supersaturated solid solution $\rightarrow$ Guinier-Preston (GP) zone $\rightarrow \theta^{\prime \prime} \rightarrow \theta^{\prime} \rightarrow \theta$ [20]. The precipitate distribution in different zones of the joint was observed using TEM, and the results are exhibited in Fig. 5. The projection of selected area diffraction is all $\mathrm{Al}<100>$. The main strong diffraction spots origin from the $\mathrm{Al}$ matrix and have been indexed.

Figure 5a shows the typical bright-field image of BM and its diffraction pattern. It is obvious that massive fine needle-like precipitates with the long axis ranging from 20 to $200 \mathrm{~nm}$ distribute in matrix dispersedly. According to the diffraction patterns of $\mathrm{BM}$, these precipitates are mainly metastable $\theta^{\prime}$ phases, and they are the primary strengthening phases due to artificial aging.
In FZ, as shown in Fig. 5b, there are the precipitates to be hardly observed. It indicates that this zone is pure $\alpha(\mathrm{Al})$ solid solution. Since no precipitate exists in this area, the lack of precipitation strengthening effect is the main softening reason of $\mathrm{FZ}$. And in HAZ adjacent to FZ, as shown in Fig. 5c, it is similar to FZ of typical bright-field image and diffraction pattern. The absence of precipitates also results in the softening of this region.

Figure 5d shows the typical bright-field image of HAZ far away from FZ and its diffraction pattern. And the precipitates of this area are also mainly metastable $\theta^{\prime}$ phases according to the diffraction pattern. Compared with Fig. 5a, precipitates are coarsened, and the amount of precipitates declines. Moreover, the precipitate evolution is regarded as the main softening factor of this region.

\subsection{Welding Thermal Cycles in HAZ}

As is known to all, the temperature plays an important role in the precipitate evolution and mechanical properties. So it is necessary to obtain the welding thermal cycles in HAZ. The traditional method is the thermocouple measurement. However, it is hard to achieve relatively intact welding thermal cycles due to the dimensional factor. On the other hand, the finite element simulation has been proved as an effective method to achieve thermal cycles in HAZ. So in this study, the welding thermal cycles in HAZ were analyzed using the Visual-Weld simulation software.

In the simulation, the full 3D models were created according to the actual joint. The grid type was hexahedral element, the number of elements was 189,450 , and the number of nodes was 208,380 . The heat source model was double-ellipsoid model that had been widely used in TIG welding simulation. And the ambient temperature was set as $25^{\circ} \mathrm{C}$. The liquidus temperature of this alloy $\left(643^{\circ} \mathrm{C}\right)$ is defined as the FL temperature. Figure $6 a, b$ shows the comparison of cross-sectional morphology between the predicted and experimental results. It can be seen that the simulation result is conformed to the actual one.

Besides, the correlation between the microhardness profile and simulation peak temperature profile along HAZ of capping weld is illustrated in Fig. 7.

It can be seen that the microhardness reaches a higher value from FL to a distance of about $1.8 \mathrm{~mm}$ where the peak temperature reaches about $545{ }^{\circ} \mathrm{C}$. This temperature is higher than the solidus temperature $\left(543{ }^{\circ} \mathrm{C}\right)$ of this alloy, so it can be inferred that the partial liquation will occur in this region, which is called partial melting zone (PMZ). Additionally, in the next $1.2-\mathrm{mm}$ region, the microhardness keeps stable in high value, and the corresponding peak temperature declines from about $545-517{ }^{\circ} \mathrm{C}$. Though no precipitate exists in FZ and the HAZ adjacent to FZ, the microhardness in HAZ adjacent to 

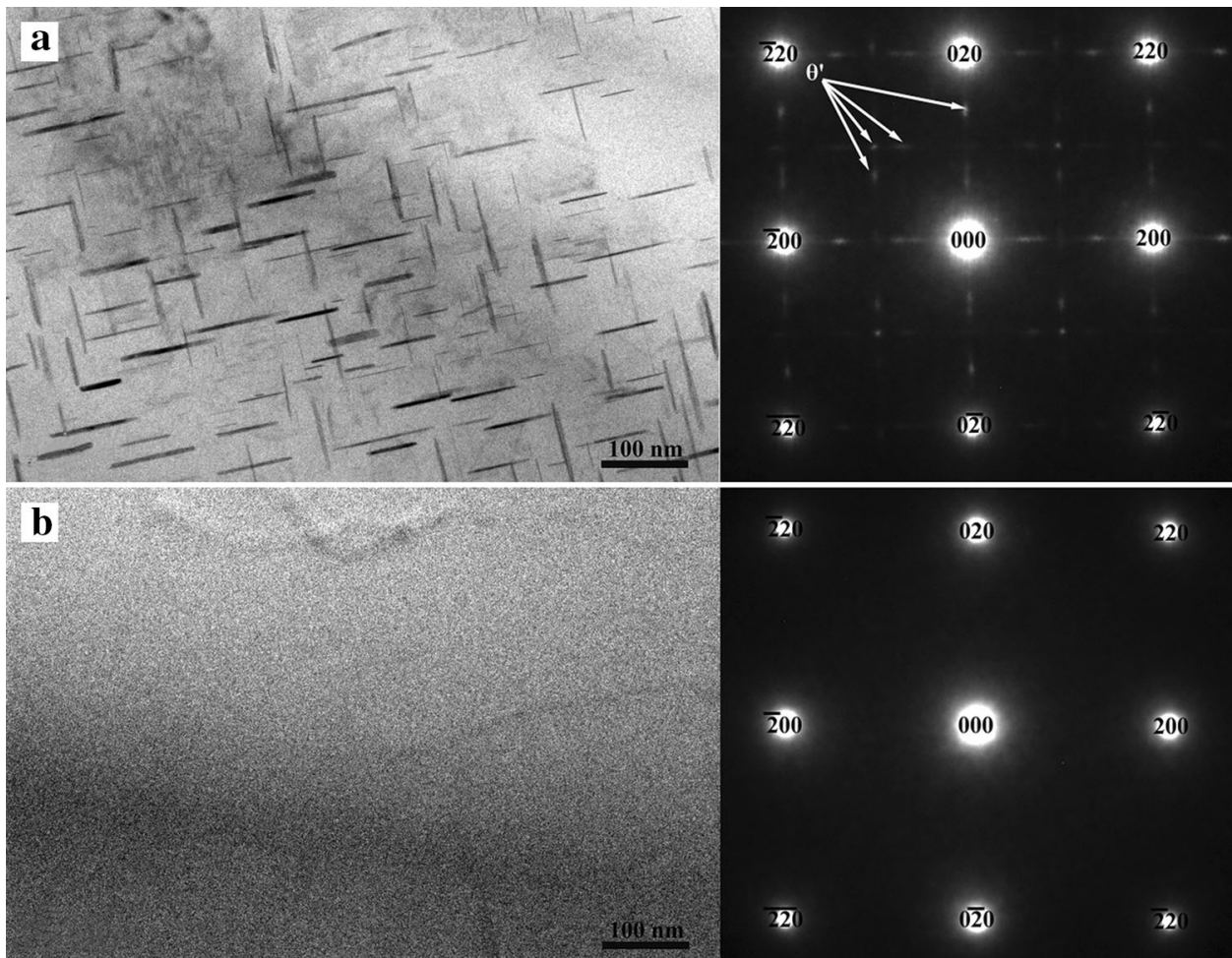

220

020

220

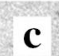

$\overline{220}$

$0 \overline{20}$

22

$$
\text { c }
$$

220

020

22
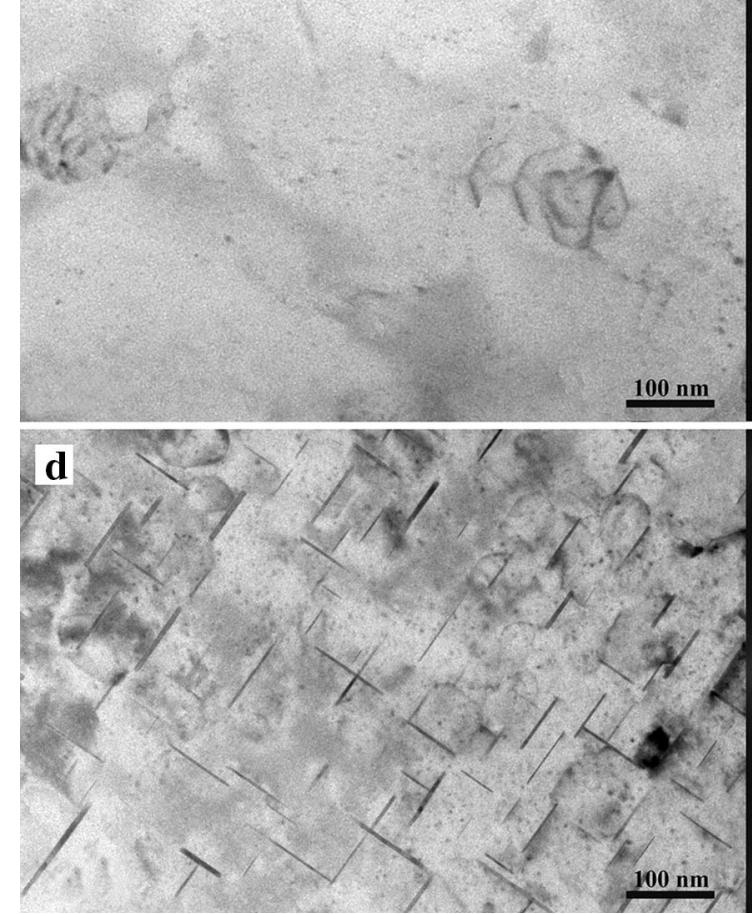

220

$0 \overline{20}$

220

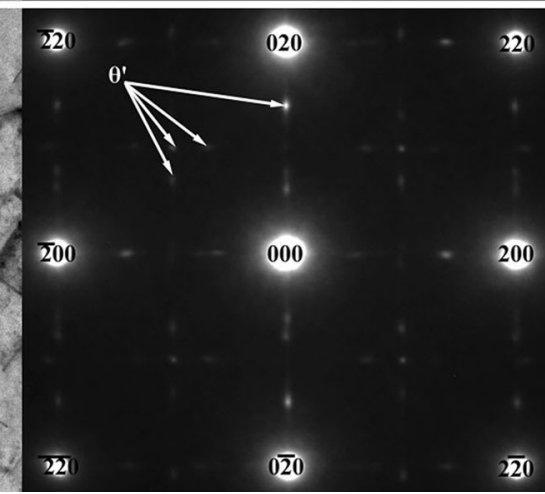

Fig. 5 TEM bright-field images and selected area diffraction patterns from different zones of the joint: a BM, b FZ, c HAZ adjacent to FZ, d HAZ far away from FZ

FZ shows higher value, and it is mainly because of solid solution strengthening effect. The pureness of the solid solution and no additional diffraction phenomenon in the SAD pattern of the matrix further confirm that this micro- area can be considered as simple solid solution with the higher degree of supersaturation. This region stayed in high temperature during the welding process, the original precipitates dissolved, and the subsequent re-precipitation was 


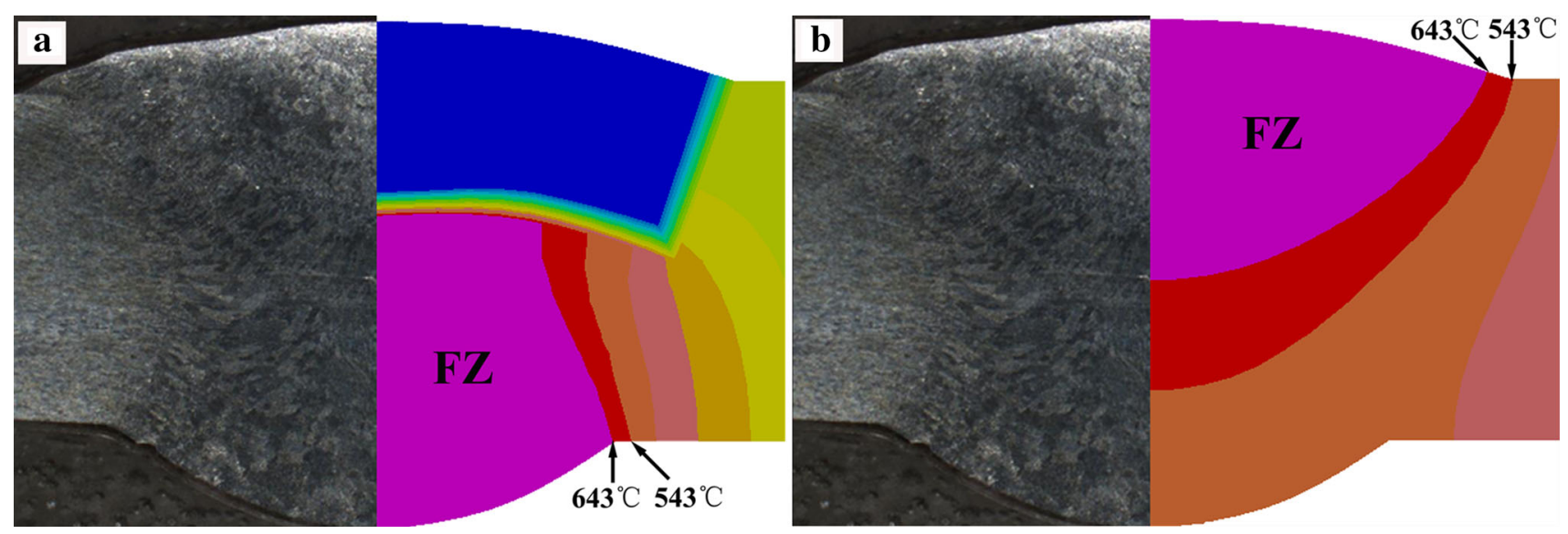

Fig. 6 Comparison of cross-sectional morphology between the predicted and experimental results: a FZ of backing weld; b FZ of capping weld
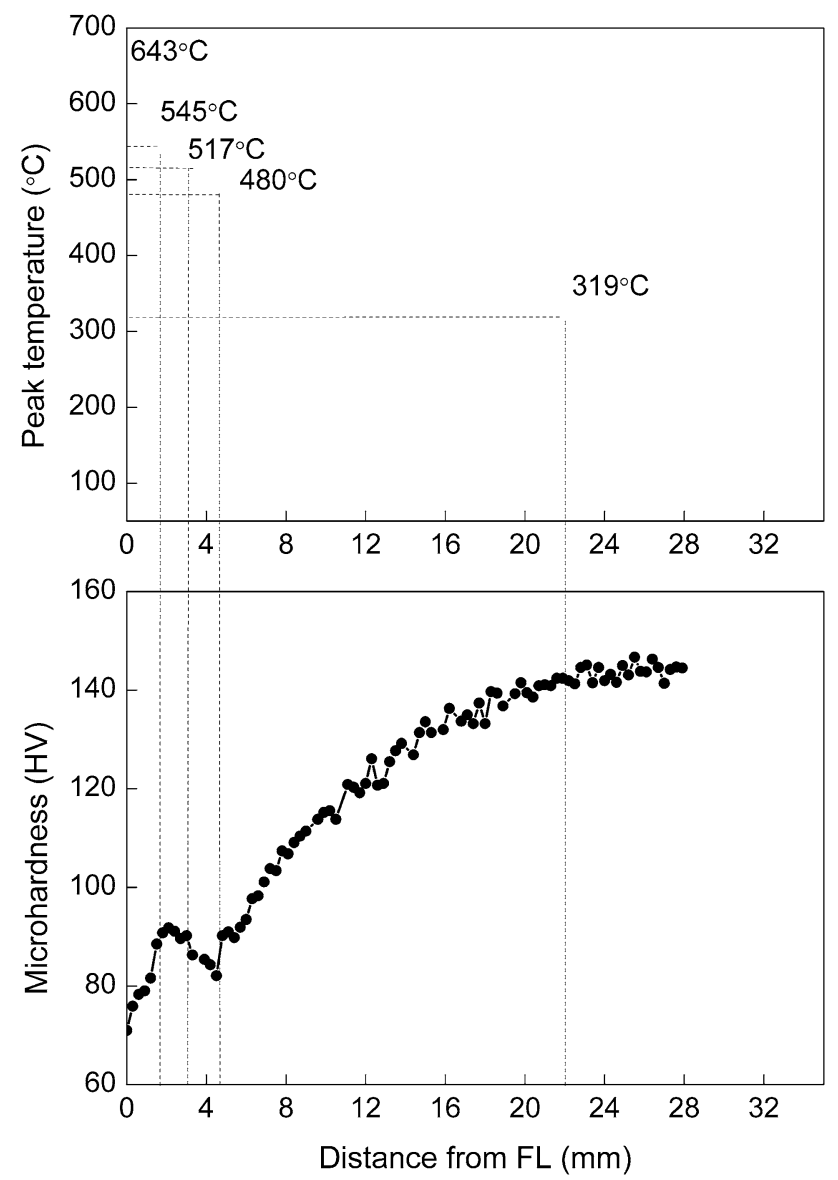

Fig. 7 Correlations between microhardness profile and peak temperature profile along HAZ

suppressed due to the high cooling rate, resulting in the formation of the supersaturated solid solution. With increasing distance to about $4.5 \mathrm{~mm}$ from FL where the peak temperature is about $480{ }^{\circ} \mathrm{C}$, the microhardness reaches a valley value. It is worth noting that this temperature is slightly higher than the initial dissolution temperature of $\theta\left(470{ }^{\circ} \mathrm{C}\right)[20,21]$. At this position, all the strengthening precipitates dissolve and coarse $\theta$ phases cause the maximum overaging effect. And then, the microhardness increases gradually from this position and reaches the edge of $\mathrm{HAZ}$ at a distance of about $22 \mathrm{~mm}$ from FL. The peak temperature is about $319{ }^{\circ} \mathrm{C}$ that is higher than the initial dissolution temperature of $\theta^{\prime}$ $\left(300{ }^{\circ} \mathrm{C}\right)[20,21]$. In this region, the needle-shaped strengthening precipitates of $\theta^{\prime}$ are coarsened, then dissolved and start to transform into balanced $\theta$ phases when temperature is higher than the initial formation temperature $\left(425^{\circ} \mathrm{C}\right)$ [20]. So with rising distance from BM, the microhardness decreases due to the weakened $\theta^{\prime}$ precipitation strengthening effect.

\section{Conclusions}

In the present work, the correlation between the microstructure characteristics and mechanical properties of the VPTIG joints was evaluated by the welding temperature field, grain size, alloying element distribution and precipitates evolution in different regions. And the main conclusions can be summarized:

1. The microhardness in the two FZs is 76 and $78 \mathrm{HV}$, respectively, and FZ is almost the weakest region of the joint.

2. There is a maximum value in the area about $1.8-3 \mathrm{~mm}$ away from the FL where the corresponding peak temperature is from 517 to $545{ }^{\circ} \mathrm{C}$. And there is also a minimum value about $4.5 \mathrm{~mm}$ away from the $\mathrm{FL}$ in the $\mathrm{HAZ}$ where the peak temperature is about $480{ }^{\circ} \mathrm{C}$. Moreover, the microhardness values reached are the same as those of BM at about $22 \mathrm{~mm}$ away from FL where the peak temperature is about $319^{\circ} \mathrm{C}$.

3. The reasons of softening of FZ are mainly grain coarsening, reduction of alloying element content, segregation of alloying element and lack of precipitates. 
4. The grain sizes of the two measured HAZs and BM are $41.5,44.9$ and $43.4 \mu \mathrm{m}$, respectively, and the reason of softening of HAZ is mainly variation of precipitates due to welding thermal cycles. In the HAZ adjacent to FZ, the microhardness shows the higher value due to the supersaturated solid solution strengthening effect despite the lack of precipitates; in the HAZ far away from FZ, the needle-shaped strengthening precipitates of $\theta^{\prime}$ are coarsened, then dissolved and start to transform into balanced $\theta$ phases, resulting in the decrease in microhardness from BM to the position with minimum hardness in HAZ.

Acknowledgement The present work was supported by the National Key Basic Research Program of China under Grant No. 2012 CB619503.

\section{References}

[1] G.V. Narayana, V.M.J. Sharma, V. Diwakar, K.S. Kumar, R.C. Prasad, Sci. Technol. Weld. Join. 9(2), 121 (2004)

[2] P.S. Rao, K.G. Sivadasan, P.K. Balasubramanian, Bull. Mater. Sci. 19(3), 549 (1996)

[3] S. Malarvizhi, K. Raghukandan, N. Viswanathan, Int. J. Adv. Manuf. Technol. 37(3), 294 (2008)

[4] H.X. Wang, Y.H. Wei, C.L. Yang, Comput. Mater. Sci. 38(4), 571 (2007)
[5] J.K. Ding, D.P. Wang, Y. Wang, H. Du, Trans. Nonferrous Metals Soc. 24(5), 1307 (2014)

[6] S. Malarvizhi, V. Balasubramanian, Trans. Nonferrous Metals Soc. 21(5), 962 (2011)

[7] S.R.K. Rao, G.M. Reddy, M. Kamaraj, K.P. Rao, Mater. Sci. Eng. A 404(1-2), 227 (2005)

[8] C.S. Paglia, R.G. Buchheit, Mater. Sci. Eng. A 429(1-2), 107 (2006)

[9] Y.C. Chen, J.C. Feng, H.J. Liu, Mater. Charact. 60(6), 476 (2009)

[10] Y.C. Chen, J.C. Feng, H.J. Liu, J. Mater. Sci. 41(1), 297 (2006)

[11] J.C. Feng, Y.C. Chen, H.J. Liu, Mater. Sci. Technol. 22(1), 86 (2006)

[12] S. Malarvizhi, K. Raghukandan, N. Viswanathan, Int. J. Fatigue 30(9), 1543 (2008)

[13] W.F. Xu, J.H. Liu, G.H. Luan, C.L. Dong, Mater. Des. 30(9), 3460 (2009)

[14] K.S. Arora, S. Pandey, M. Schaper, R. Kumar, J. Mater. Sci. Technol. 26(8), 747 (2010)

[15] S. Malarvizhi, V. Balasubramanian, Weld. World 56(9), 105 (2012)

[16] Q. Li, A.P. Wu, Y.J. Li, G.Q. Wang, Mater. Sci. Eng. A 623(19), 38 (2015)

[17] R. Konar, M. Mician, J. Strasko, Int. J. Appl. Mech. Eng. 15(2), 423 (2010)

[18] S.K. Bate, R. Charles, A. Warren, Int. J. Press. Vessles Pip. 86(1), 73 (2009)

[19] D.K. Xu, P.A. Rometsch, N. Birbilis, Mater. Sci. Eng. A 534(1), 234 (2012)

[20] J.M. Papazian, Metall. Trans. A 12(2), 269 (1981)

[21] S.P. Ringer, K. Hono, Mater. Charact. 44(1-2), 101 (2000) 